\title{
Encoding and Retrieval of Episodic Memories: Role of Cholinergic and GABAergic Modulation in the Hippocampus
}

\author{
Michael E. Hasselmo, Bradley P. Wyble, \\ and Gene V. Wallenstein \\ Department of Psychology and Program in Neuroscience, \\ Harvard University, Cambridge, Massachusetts
}

\begin{abstract}
This research focuses on linking episodic memory function to the cellular physiology of hippocampal neurons, with a particular emphasis on modulatory effects at cholinergic and $\gamma$-aminobutyric acid B receptors. Drugs which block acetylcholine receptors (e.g., scopolamine) have been shown to impair encoding of new information in humans, nonhuman primates, and rodents. Extensive data have been gathered about the cellular effects of acetylcholine in the hippocampus. In this research, models of individual hippocampal subregions have been utilized to understand the significance of particular features of modulation, and these hippocampal subregions have been combined in a network simulation which can replicate the selective encoding impairment produced by scopolamine in human subjects. ๑ 1997 Wiley-Liss, Inc.
\end{abstract}

KEY WORDS: free recall, recognition, acetylcholine, presynaptic inhibition, medial septum, feedback, attractor dynamics

\section{INTRODUCTION}

Like many articles in this issue, this work presents models linking behavioral data on memory function to specific features of the cellular physiology of hippocampal neurons. This article focuses on the role of acetylcholine in hippocampal memory function. Focusing on a specific neuromodulatory substance allows data on the effects of pharmacological manipulations in behavioral experiments (Ghoneim and M ewaldt, 1975; Sutherland et al., 1982; Aigner et al., 1991; $\mathrm{H}$ asselmo, 1995) to be related directly to data on the cellular effects of pharmacological manipulations in brain slice preparations of the hippocampus (Yamamoto and Kawai, 1967; H ounsgaard, 1978; Madison and Nicoll, 1984; H asselmo and Schnell, 1994; $\mathrm{H}$ assel mo et al., 1995).

\section{BEHAVIORAL DATA}

D rugs which block muscarinic acetylcholine receptors have been demonstrated to selectively impair the encoding but not the retrieval of new

Accepted for publication July 15, 1996.

Address correspondence and reprint requests to Michael E. Hasselmo, Dept. of Psychology, Rm. 984, Harvard University, 33 Kirkland St., Cambridge, MA 02138. information in a wide range of different behavioral tasks. For example, in a series of studies (Ghoneim and Mewaldt, 1975; Peterson, 1977; Ghoneim and Me waldt, 1977; M ewaldt and Ghoneim, 1979), human subjects were sequentially presented with individual words from a set of lists. They then received an injection of scopolamine. O ne half hour later, under the influence of scopolamine, they were tested on their delayed free recall of that list of words, and showed no retrieval impairment relative to control subjects. H owever, they were subsequently trained on a second set of word lists and tested for their delayed free recall of this second set of words - encoded under the influence of scopolamine. The free recall of this second set of words was strongly impaired-subjects who learned the second list under the influence of scopolamine generated only an average of six out of 128 words, whereas subjects who learned the list after an injection of saline generated an average of 45 words. In addition to the spared retrieval of information learned before the injection, scopolamine also appears to spare semantic memory and short-term memory phenomena such as the recency component of a serial position curve (Crow and GroveW hite, 1973; Frith et al., 1984) and digit span (D rachman, 1978; Beatty et al., 1986).

A similar selective impairment of encoding has been demonstrated in experiments testing episodic memory for visual objects in monkeys (Aigner et al., 1991) and episodic memory for platform location in the Morris water maze in rats (Wishaw, 1989; Sutherland et al., 1982). Systemic injections of scopolamine influence a wide variety of brain structures, but data suggest that it is appropriate to focus on cholinergic modulation within the hippocampus. In human subjects hippocampal lesions have a selective effect on memory similar to that of scopolamine, impairing delayed free recall, while sparing semantic memory, recency, and digit span (Baddeley and Warrington, 1970; Corkin, 1984). In monkeys, episodic memory for visual objects is impaired by lesions of the hippocampus (Alvarez et al., 1994, 1995) as well as lesions of the fornix ( $G$ affan and H arrison, 1989) - a primary effect of which is destruction of much of the cholinergic innervation of the 
hippocampus. Ablation of the cholinergic innervation of the hippocampus from the medial septum impairs encoding of place information in the rat ( $\mathrm{H}$ agan et al., 1988), and inactivation of the medial septum with tetracaine injection selectively impairs the acquisition but not the maintenance of spatial memories in rats (M izumori et al., 1990). Thus, effects of cholinergic blockers on memory function may be due to blockade of cholinergic modulation within the hippocampus.

\section{BRAIN SLICE PHYSIOLOGY}

Understanding behavioral data is the long-term goal of this computational modeling work. However, in contrast to many previous models of memory function (M etcalfe and Murdock, 1981; Gillund and Shiffrin, 1984; Ruppin and Yeshurun, 1991; Chappell and Humphreys, 1994), we wish to address this data from the viewpoint of another body of experimental data- data on cellular effects of acetylcholine obtained in brain slice preparations. The hippocampal slice preparation has been used to explore how acetylcholine influences cellular physiology. Similar effects have been found in another threelayered cortical structure: the piriform cortex. Thenetwork models presented here have incorporated all of the following effects of acetylcholineat muscarinic receptors:

1. Acetylcholine suppresses excitatory synaptic transmission. Activation of presynaptic muscarinic receptors appears to decrease the release of glutamate from presynaptic terminals at a subset of hippocampal terminals. In brain slice preparations, this results in a decrease in the size of synaptic potential selicited by stimulation of stratum radiatum in region CA1 (H ounsgaard, 1978; Valentino and D ingledine, 1981; H asselmo and Schnell, 1994) and stratum radiatum in region CA3 (H asselmo et al., 1995). The suppression of synaptic transmission appears to be weaker in stratum lacunosum-moleculare of CA1 (H asselmo and Schnell, 1994). Similar laminar selectivity appears in the piriform cortex ( $\mathrm{H}$ asselmo and Bower, 1992) and neocortex (H asselmo and C ekic, 1996).

2. Acetylcholine suppresses neuronal adaptation. Activation of postsynaptic muscarinic receptors appears to decrease a calciumdependent potassium current in hippocampal pyramidal neurons, resulting in more sustained firing in response to a depolarizing input (M adison and N icoll, 1984; M adison et al., 1987). Similar suppression of neuronal adaptation appears in the piriform cortex (Barkai and H asselmo, 1994) and neocortical structures (Schwindt et al., 1988).

3. Acetylcholine depolarizes pyramidal cells and interneurons. Perfusion of the slice chamber with cholinergic agonists (or stimulation of cholinergic innervation) causes a slow, long-lasting depolarization (Coleand N icoll, 1984; Benardo and Prince, 1982). Similar depolarization appears in the piriform cortex (Barkai and $\mathrm{H}$ asselmo, 1994).

4. A cetylcholine enhances synaptic modification. In the presence of cholinergic agonists, the magnitude of long-term potentiation is enhanced in stratum radiatum of region CA1 (Blitzer et al., 1990) and stratum moleculare of the dentate gyrus (Burgard and Sarvey, 1990). Similar enhancement of synaptic modification has ben demonstrated in the piriform cortex (H asselmo and Barkai, 1995).
These effects of cholinergic activation of muscarinic receptors are assumed to be blocked by systemic administration of the muscarinic receptor antagonist scopolamine. Thus, in simulating the effects of scopolamine, the cellular effects of acetylcholine are reduced in magnitude within the model.

These models should be evaluated on the basis of their ability to simultaneously address the qualitative features of cholinergic modulation at the cellular level and the effect of blocking cholinergic modulation at the behavioral level. $M$ any other memory models emphasize the issue of capacity (Amit, 1989; Treves and Rolls, 1994)-making the assumption that these networks are optimized for capacity. H owever, the information capacity of the hippocampus is not an experimentally measurable quantity. The capacity of short-term memory has been measuredbut the hippocampus does not appear to be crucial to short-term memory. Lesions of the hippocampus do not appear to influence digit-span or the recency component of the serial position curve in humans or rats (Baddeley and Warrington, 1970; Kesner and N ovak, 1982). The capacity of consolidated long-term memory appears to exceed the size of any testable data set, and data on graded retrograde amnesia suggests that consolidated long-term memory does not depend upon the hippocampus (Scoville and M ilner, 1957; Corkin, 1984; reviewed in McClelland et al., 1995). The hippocampus appears to be involved in intermediateterm storage of information (Eichenbaum et al., 1989, 1991, 1992, 1994; Eichenbaum and Buckingham, 1990) which is subsequently passed back to neocortical structures. It would be difficult to measure the capacity of intermediate-term memory, since it would involve determining the exact quantity of information loss due to a hippocampal lesion. In contrast, this modeling research focuses on addressing the dynamics of memory storage. We expect these models to be evaluated in terms of their ability to simulate the stages of encoding and retrieval of episodic memories (represented by overlapping binary patterns). In addition, the models should be evaluated on the basis of the qualitative description of psychopharmacological effects.

\section{MODELS OF CHOLINERGIC MODULATION IN THE HIPPOCAMPUS}

This section will start with an overview of a full hippocampal model of episodic memory function. Subsequently, models of the function of cholinergic modulation within individual hippocampal subregions will be discussed. Finally, this section will briefly summarize a large-scale network simulation of the dynamic interaction of all hippocampal subregions, which has been used to replicate the effects of scopolamine on human memory function.

\section{Overview of the Model}

This modeling research has focused on the episodic memory function of the hippocampal formation. Thus, the model ad- 
dresses behavioral data including some of the data addressed by more abstract models of the performance of human subjects in free recall and recognition (M etcalfe and M urdock 1981; Gillund and Shiffrin, 1984; Chappell and H umphreys, 1994). At the same time, as described below, this model is closely related to many previous theories of the function of individual hippocampal subregions (M arr, 1971; M CN aughton and M orris, 1987; Levy, 1989; Eichenbaum and Buckingham, 1990; M CN aughton, 1991; Treves and Rolls, 1992; O 'Reilly and M cC lelland, 1994; M cClelland et al., 1995; M cClelland and Goddard, 1996). H owever, in implementing a hippocampal simulation of human episodic memory function, we have addressed many additional issues not addressed in any of these previous theoretical articles.

At a circuit level, the network model of hippocampus involves two basic processes, which are here referred to as self-organization and associative memory function. Perforant path synapses undergo sequential self-organization, setting up sparser, less overlapping representations of individual input patterns. M odification of excitatory synapses in region $\mathrm{CA} 3$ and region $\mathrm{CA} 1$ mediates associative memory function, allowing different sparse representations to be associated with one another. In this model, this allows the network to retrieve individual items based on experimental context (simulation of free recall) and to retrieve the previously encoded experimental context when presented with individual items (simulation of recognition).

These two functions of the model are related to previous modeling research on self-organization ( $O$ 'Reilly and $\mathrm{M}$ cClelland, 1994; Troyer, 1996) and associative memory function (Anderson et al., 1977; H opfield, 1982; Treves and Rolls, 1992). H ere these functions can bedefined with regard to a single variable- thelevel of synaptic transmission at modifiable synapses (H asselmo, 1995). In self-organization, the modifiable synapses are the primary influence on postsynaptic activity during learning. In associative memory function, the modifiable synapses are N OT the primary influence on postsynaptic activity during learning. Thus, modulation of synaptic transmission plays an important role in setting the functional characteristics of different sets of synapses.

Figure 1 shows the structure of the hippocampus and a schematic diagram of the hypothesized function of different hippocampal subregions in the model. These hypotheses are based primarily on the nature of anatomical connectivity within the different subregions (see Amaral and W itter, 1989, for anatomical review). Entorhinal cortex is the primary input and output structure in the model. Entorhinal cortex layer II receives the input patterns to be encoded and the cues to be used during retrieval. 0 utput activity in entorhinal cortex layer IV is eval uated to analyze the success of retrieval from the model.

Sequential self-organization of the perforant path connections from the entorhinal cortex to the dentate gyrus and region CA1 mediates formation of sparse representations of individual input patterns. Thus, small subsets of neurons in the dentate gyrus become selectively responsive to each random pattern of activity presented to entorhinal cortex layer II. As in previous articles (MCN aughton and Morris, 1987; O'Reilly and McClelland, 1994), this assumption is based on the large fan out from entorhinal cortex to dentate gyrus and the sparser responsiveness of the dentategyrus ( $\mathrm{M}$ cN aughton and Barnes, 1990; Q uirk et al., 1992). The sparse activity patterns in the dentate gyrus represent the features of an individual episodic memory-for example, the learning of a single word in a list learning experiment. $N$ ote that these are not semantic representations of the word which would be activated in a wide range of different contexts- rather, they code the activation of the semantic representation in a specific episode. As described below, in each region of the model, different subsets of neurons represent individual stored memories and the shared context. This separation of item and context proves important for simulating the mechanisms of free recall and recognition.

Activity is passed from the dentate gyrus to region CA3, where excitatory recurrent connections representing the longitudinal association fibers mediate auto-associative memory function. The structure of this portion of the model is based on the strong and focused connectivity of the mossy fibers within the dentate gyrus and the high percentage of recurrent connectivity (reviewed in Treves and Rolls, 1992). This allows individual representations of items to be associated with experimental context or other items. At the same time, modification of the connections from region CA3 to region CA1, representing the Schaffer collaterals, associates the patterns of activity in region $\mathrm{CA} 3$ with self-organized representations in region CA1. This formation of associations between CA3 activity and entorhinal cortex input allows implementation of a comparison in region CA1 between the attractor states generated during recall in region $\mathrm{CA} 3$ and the direct afferent input from entorhinal cortex. A comparison function has been discussed previously for this region (Levy, 1989; Eichenbaum and Buckingham, 1990), but this model is the first to make specific use of such a comparison in setting appropriate dynamics for encoding and retrieval. Finally, the self-organized representations formed in region CA1 are associated with activity in entorhinal cortex layer IV (which receives direct input of layer II activity). This allows the sparse representations of the hippocampus to evoke patterns of output activity in entorhinal cortex layer IV corresponding to the full learned input patterns (see related discussion of invertibility in M cClelland and G oddard, 1996).

In addition to representations of these different subregions, the model includes representation of the modulatory cholinergic input from the medial septum. This cholinergic input induces the full range of physiological effects listed in the introduction, including suppression of excitatory and inhibitory synaptic transmission, suppression of neuronal adaptation, depolarization of pyramidal cells and interneurons, and enhancement of synaptic modification. This article focuses on the suppression of excitatory synaptic transmission, but modeling work has also analyzed the role of suppression of adaptation and depolarization on network function (Barkai and $\mathrm{H}$ asselmo, 1994; $\mathrm{H}$ asselmo and Barkai, 1995). The models discussed here include simulation of this depolarization and can therefore simulate the enhancement of response to perforant path stimulation during medial septal stimulation (Bilkey and Goddard, 1985) and the decrease in granule cell and CA3 activity after reversible inactivation of the medial septum (M izumori et al., 1989). In the model, removing septal input decreases responsiveness to novel input patterns, while familiar input patterns continue to cause robust activation. 
M ore recent biophysical simulations have incorporated theta rhythm dynamics to address the changes in excitability observed during different phases of the theta cycle (Rudell et al., 1980; Stewart and Fox, 1990).

\section{Function of Hippocampal Subregions}

This section reviews individual modeling projects focused on the role of cholinergic modulation within individual hippocampal subregions.

\section{Cholinergic modulation of the Schaffer collaterals}

The first model of cholinergic modulation within a hippocampal subregion addressed cholinergic effects at the Schaffer collaterals (H asselmo and Schnell, 1994). The Schaffer collaterals have been the focus of a wide range of physiological research, including extensive studies of the mechanisms of long-term potentation
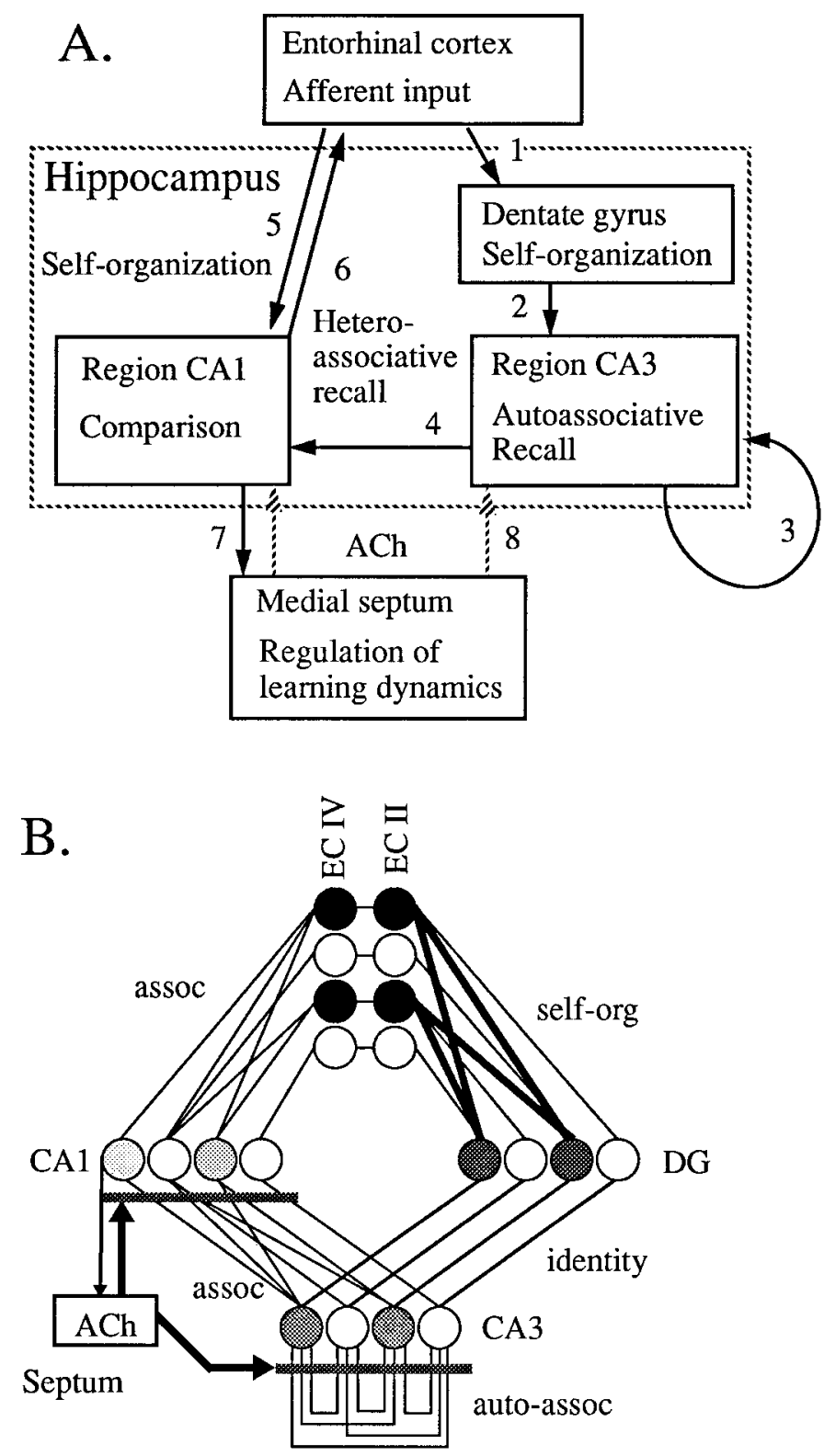

(W igstrom et al., 1986). H owever, relatively few researchers have proposed a specific function for modification of the Schaffer collaterals. The model presented here evaluates a function proposed by McNaughton (1991): that the Schaffer collaterals mediate hetero-associative memory function- storing associations between patterns of activity in region CA3 and patterns of activity induced in region $\mathrm{CA}$ l by the perforant path input from the entorhinal cortex. This contrasts with other views which focus more on self-organization of the Schaffer collaterals (Treves and Rolls, 1994; Treves, 1995).

Modeling demonstrates that the putative heteroassociative memory function of the Schaffer collaterals would be greatly enhanced by selective cholinergic suppression of synaptic transmission in stratum radiatum of region CA1 (H asselmo and Schnell, 1994). This was tested in a simplified model containing threshold linear neurons representing pyramidal cells of region $\mathrm{CA} 1$, as summarized in Figure 2. Input to the structure arrived from simplified representations of region CA3 and entorhinal cortex layer III. To test the heteroassociative memory function of the network, patterns of activity were presented simultaneously to both region CA3 and entorhinal cortex, or separately to just one input region. The input to region $\mathrm{CA} 3$ was representative of the mossy fiber input from dentate gyrus granule cells to CA3 pyramidal cells- note that this activity is related to entorhinal cortex activity but has been transformed by the dentate gyrus. Effective heteroassociative memory function occurred when patterns of activity presented to region $\mathrm{CA} 3$ were able to retrieve patterns of activity in region CA1 corresponding to previously associated input patterns from entorhinal cortex. This perfor-

FIGURE 1. A: Function of different hippocampal subregions in these computational models. 1. Fibers of the perforant path connect entorhinal cortex layer II with the dentate gyrus. These undergo rapid self-organization to form new representations of patterns presented sequentially to entorhinal cortex. 2. The dentate gyrus projects to region CA 3 via the mossy fibers. These connections pass the sparse representations on to region CA3 for autoassociative storage. 3. Longitudinal association fibers connect pyramidal cells within region CA3, mediating auto-associative storage and recall of CA3 patterns of activity. 4. The Schaffer collaterals connect region CA3 with region CA1 and mediate heteroassociative storage and recall of associations between activity in CA3 and the self-organized representations formed by entorhinal input to CA1. 5. Perforant path connections also enter region CA1 from the entorhinal cortex. These undergo self-organization to form new representations of entorhinal cortex input for comparison with recall from CA3. 6. Projections back from region CAI enter layer IV of the entorhinal cortex either directly, or via the subiculum. These store associations between CA1 activity and entorhinal cortex activity, allowing representations in CA1 to activate the associated activity patterns in entorhinal cortex layer IV. 7. Region CA1 can influence activity in the medial septum either directly, or via connections with the lateral septum, allowing a mismatch between recall and input to increase $A C h$, and a match between recall and input to decrease $\mathrm{AC}$. 8. The medial septum (and the vertical limb of the diagonal band of Broca) provides cholinergic modulation to all hippocampal subregions. B: Connectivity structure of the model. Groups of units in each region represent populations of simulated pyramidal cells in the model. Each population of pyramidal cells is associated with separate inhibitory interneurons mediating feedforward and feedback inhibition. 

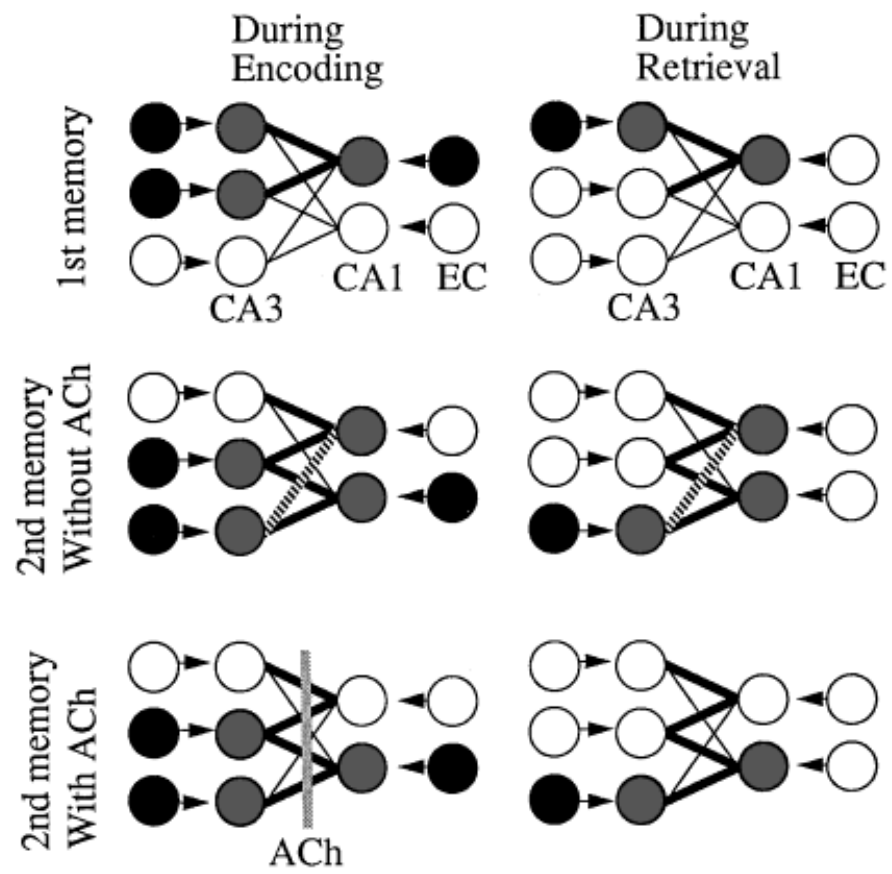

FIGURE 2. Example of how cholinergic modulation enhances heteroassociative memory function at the Schaffer collaterals. This example shows a simplified version of region $C A 1$, receiving input from entorhinal cortex (EC) and from region CA3 via the Schaffer collaterals. 1st memory: During learning of a 1st memory, two neurons in region CA3 are activated, and input from EC activates a single neuron in region CA1. Hebbian modification of Schaffer collateral synapses stores the association between CA3 activity and EC input (thicker lines). D uring recall, a degraded version of CA3 activity containing only one active neuron can recall the previously associated pattern of CA1 activity (even with no EC input). 2nd memory without $\mathrm{ACh}$ : Learning of a second overlapping association suffers from interference. When the overlapping pattern is presented to region CA3, retrieval of the previous association takes place due to spread of activity along previously strengthened connections. H ebbian synaptic modification then results in strengthening of an additional undesired connection (dashed line). This additional connection means that an unambigious cue presented to region CA3 ends up retrieving elements of both stored memories. 2nd memory with ACh: Cholinergic suppression of synaptic transmission at the Schaffer collaterals can prevent this interference during encoding. D uring learning, suppression prevents spread of activity into region CA1 from region CA3, allowing strengthening of only desired connections (the suppression must leave sufficient transmission to allow synaptic modification). D uring recall, cholinergic suppression is removed, and the network can effectively retrieve the 2nd association when presented with the nonoverlapping component of CA3 activity.

mance was evaluated using a measure based on normalized dot products which evaluated the encoding and retrieval of associations between random overlapping input patterns. This performance measure shows higher values for more accurate retrieval of individual stored associations.

Figure 3A shows the performance of the network with different values of cholinergic suppression of synaptic transmission in stratum radiatum (at the Schaffer collaterals) and different values of suppression of synaptic transmission in stratum lacunosummoleculare (the location of perforant path synapses from the entorhinal cortex). Note that the highest performance values appear for relatively high levels of the cholinergic suppression of synaptic transmission in stratum radiatum, but for lower values of cholinergic suppression in stratum lacunosum-moleculare.

These results from the model were compared with experimental data on synaptic potentials recorded in stratum radiatum and stratum lacunosum-moleculare of a hippocampal brain slice preparation during perfusion with cholinergic agonists. As shown in Figure 3B, experimental data show that cholinergic suppression of synaptic potentials is much stronger in stratum radiatum than in stratum lacunosum-moleculare. The relative effect on synaptic transmission in these two layers is plotted in Figure $3 \mathrm{~A}$, showing that at physiologically realistic concentrations, the plot crosses a region of high performance in the model.

This modulatory function may not be unique to acetylcholine. In brain slice preparations of the piriform cortex and the hippocampus, activation of presynaptic $\gamma$-aminobutyric acid $B$ $\left(G A B A_{B}\right)$ receptors by the $G A B A_{B}$ agonist baclofen has been shown to selectively suppress synaptic potentials. Thus, baclofen selectively suppresses intrinsic but not afferent fiber synaptic transmission in the piriform cortex (Tang and $\mathrm{H}$ asselmo, 1994) and similarly suppresses synaptic transmission at synapses arising from region CA3 pyramidal cells more than transmission at perforant path synapses in stratum lacunosum-moleculare (Ault and Nadler, 1982; Colbert and Levy, 1992). This selective suppression of synaptic transmission could contribute to setting appropriate dynamics for encoding of new information.

\section{Feedback regulation of cholinergic modulation}

This model utilized feedback regulation of cholinergic modulation to set appropriate dynamics for encoding and retrieval. M ost associative memory models set the dynamics of the network externally (Anderson et al., 1977; H opfield, 1982; Amit, 1989). That is, these models clamp the activity of the network to the input pattern during encoding, and then allow modified connections to influence activity during retrieval. If learning dynamics are not clamped, the networks can function well for a period of time, but ultimately show a breakdown in function referred to as runaway synaptic modification (H asselmo, 1995). O nly a few abstract models have addressed the problem of switching between different dynamics for encoding and retrieval (M urre et al., 1992; Carpenter and Grossberg, 1993).

In the model presented here, the total activity in region CA1 regulated the levels of cholinergic modulation in the network. For novel patterns, activity levels in region CA1 were low, and cholinergic modulation stayed high initially. As the pattern became encoded, the level of activity in region CA1 would increase and cholinergic modulation would decrease, allowing a transition from encoding to retrieval dynamics. Presentation of familiar input patterns caused higher levels of activity in region CA3 due to a match with previously strengthened connections and higher levels of activity in region CA1 due to a match between the pattern of activity spreading from CA3 to CA1 and the pattern of activity from entorhinal cortex. Via feedback connections with the medial septum, higher activity in region CA1 
A

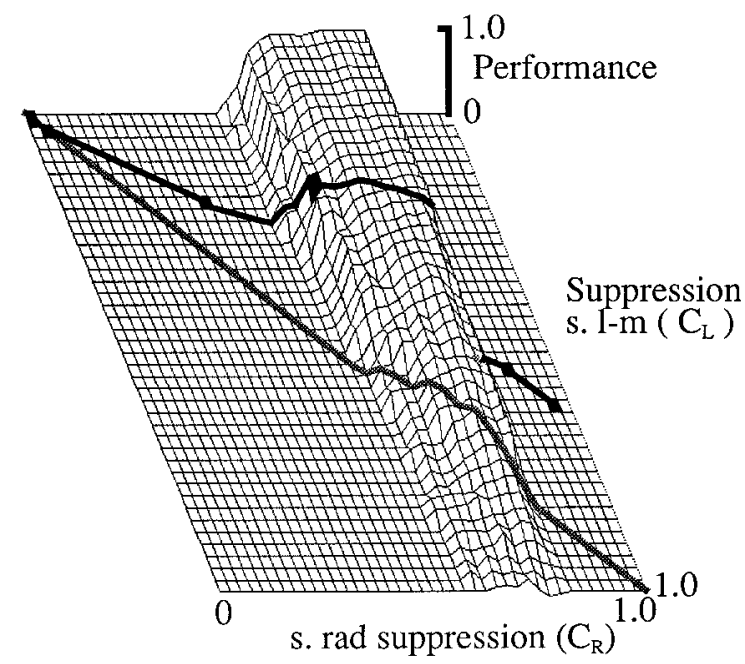

B
S. Lacunosum-Moleculare

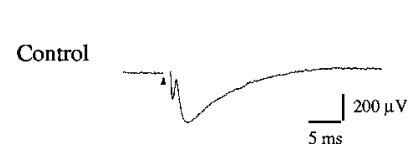

$100 \mu \mathrm{M}$ Carbachol

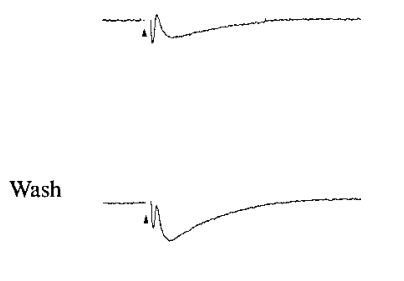

S. Radiatum
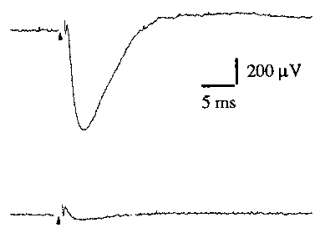

$+$

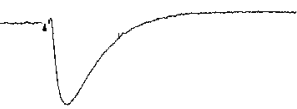

FIGURE 3. A: Performance measure of heteroassociative memory function for different values of maximal cholinergic suppression of synaptic transmission in stratum lacunosum-moleculare (s.l-m, $C_{L}=0.0$ to 1.0 ), plotted on the $y$ axis, and stratum radiatum (s. rad, $C_{R}=0.0$ to 1.0), plotted on the $x$ axis. The $z$ axis shows the value for each simulation of the performance measure $P$ (based on normalized dot products). The best performance ( $P>0.8)$ appears with strong maximal cholinergic suppression in stratum radiatum $\left(C_{R}=0.575\right.$ to 0.8 ) and weak maximal suppression in stratum lacunosummoleculare $\left(C_{L}=0.0\right.$ to 0.425$)$. For low values of $C_{R}$ (left side, $\left.C_{R}<0.5\right)$, interference during learning causes the network to respond to all $C A 3$ patterns with broadly distributed activity in $C A 1$, giving low performance values. For high values of $C_{L}$ (bottom portion, $\left.C_{L}>0.6\right)$, insufficient EC input prevents accurate learning of associations, giving low performance values. For very high values of $C_{R}\left(C_{R}>0.8\right)$ suppression in stratum radiatum prevents sufficient activity in CA1 for decreasing cholinergic suppression and allowing recall. Gray line represents unity $\left(C_{L}=C_{R}\right)$. Whiteline represents the dose response plot from experimental data plotted on these coordinates. B: The cholinergic agonist carbachol suppresses synaptic potentials stimulated and recorded in s. radiatum more strongly than synaptic potentials stimulated and recorded in s. lacunosummoleculare of the same slice during the same experiment. Recordings in the two layers were taken before, during, and after perfusion of 100 $\mu \mathrm{M}$ carbachol. In this slice, the slope of the s. radiatum EPSP was suppressed by $90.7 \%$, while the slope of the s. I-m EPSP was suppressed by only $46.0 \%$ during the same perfusion. Fiber potentials remained stable during carbachol perfusion in both layers in both slices. Potentials recovered after 20 min of wash. caused greater inhibition of the cholinergic input from the septum, allowing retrieval dynamics to dominate from the start.

Unfortunately, there are not extensive data available on the effect of hippocampal activity on medial septal activity. N egative feedback appears reasonable based on data showing that stimulation of the fimbria decreases medial septum unit activity (M cLennan and Miller, 1974). However, this aspect of the model requires further empirical investigation. In fact, the feedback regulation may be less important than rhythmic changes in dynamic state during the course of the theta rhythm, which appears to be driven by the input from the medial septum (Stewart and Fox, 1990; Buzsaki et al., 1984; Bland and Colom, 1993). Presumed cholinergic neurons show phasic activity which could alter acetylcholine levels in the hippocampus during different phases of the theta rhythm (Stewart and Fox, 1989).

Some data suggest that acetylcholine effects are too slow to change during the course of the theta rhythm (Cole and Nicoll, 1994), but an alternative exists. Local release of GABA within the hippocampus can modulate synaptic transmission in a manner similar to acetylcholine, via activation of presynaptic $G A B A_{B}$ receptors which suppress excitatory synaptic transmission with a laminar specificity similar to that of cholinergic effects (Ault and Nadler, 1982; Colbert and Levy, 1992). Phasic excitation and inhibition of hippocampal interneurons by septal input could change levels of GABA on the time scale of the theta rhythm (Stewart and Fox, 1990). This could allow a regular cyclical change in dynamics from encoding to retrieval within each theta cycle. These cyclical changes would involve an ongoing interaction of the level of excitatory synaptic transmission and the level of cellular excitability. During the encoding phase of the cycle, neurons would be more depolarized and responsive to afferent input (Rudell et al., 1980; Stewart and Fox, 1990), but the suppression of synaptic transmission would prevent extensive recurrent activation. During the retrieval phase of the cycle, neurons would be less depolarized and less responsive to afferent input, but would be driven strongly by excitatory recurrent transmission. M odels are currently being used to explore whether this forced cyclical change in dynamics has the same functional role as changes regulated by negative feedback.

\section{Associative memory and region CA3 longitudinal association fibers}

Cholinergic modulation in region CA3 has been analyzed in a separate study (H asselmo et al., 1995). Based on the broad distribution and high percentage of connectivity found in region CA3, a number of researchers have proposed that the longitudinal association fibers of region CA3 mediate auto-associative memory function (M arr, 1971; M cN aughton and M orris, 1987; Levy et al., 1990, 1995; Treves and Rolls, 1992, 1994). H ebbian synaptic modification of the excitatory recurrent connections within region CA3 allows storing of associations between different components of the representation arriving from the dentate gyrus. N etworks of this type can demonstrate attractor dynamics - the ability to enter a stable self-sustained activity state. This can be accomplished by assuming normalization of total activity (Treves and Rolls, 1992), by setting appropriate parameters for feedback inhibition medi- 
ated by inhibitory interneurons ( $\mathrm{H}$ asselmo et al., 1995) or by allowing cyclical phases of excitation and inhibition (Granger et al., 1996). Sustained cyclical activity has also been generated in a model of the piriform cortex (Liljenstrom and $\mathrm{H}$ asselmo, 1995).

In the model of region $\mathrm{CA} 3$, different memory states were assumed to correspond to individual attractor states. These attractor states were formed by strengthening the excitatory recurrent connections in this region during the initial input of a pattern (representing the input from dentate gyrus). Cholinergic suppression of feedback excitation is important in this model to prevent previously stored attractor states from dominating and preventing the formation of new attractor states.

As shown in Figure 4, when cholinergic modulation in the network is set at low values, the attractor dynamics dominatepushing the network into a previously stored activity pattern. When cholinergic modulation is set at higher values, the new input pattern can more effectively influence the pattern of activity during encoding. This allows formation of a new attractor state, without elements of the previously stored attractor state. In the model, the default state is one of high cholinergic modulation, suppressing old attractors. Thus, only when a match is obtained is the cholinergic modulation reduced.

This work was done with an abstract continuous firing rate model. In more recent work we have developed a detailed compartmental biophysical simulation using a reduced Traub model (Traub et al., 1991). The model has been found to exhibit a variety of population behaviors. Globally synchronized burst oscillations in pyramidal cells that resemble epileptiform activity in hippocampal slice preparations (Swartwelder et al., 1987) have been observed during simulated cholinergic suppression of the adaptation currents which normally support the after-hyperpolarization in these cells. When cholinergic suppression of excitatory

FIGURE 4. Cholinergic modulation determines whether a model of region CA3 goes into old attractor states or forms new attractor states. Afferent input patterns are shown at top, with black squares representing active input lines. Pattern 1 and 2 each contain four active input lines, with two lines in common between the patterns. Degraded versions of the input patterns are lacking two active input lines. Pattern of activity in the network during sequential presentation of pattern 1, degraded pattern 1, pattern 2, and degraded pattern 2. The activity of each of ten excitatory neurons (Excit), two inhibitory neurons (Inhib), and one cholinergic neuron (ACh) is shown for every 50th simulation step, with size of black squares representing activity level. A: With no cholinergic modulation, activity tends toward previously stored patterns (input to $\mathrm{ACh}$ neuron $=0.0$ ). D uring presentation of pattern 1 , the network shows lower activity until synaptic calcium crosses threshold, strengthening excitatory feedback and causing an increase in activity. Subsequent presentation of a degraded version of pattern 1 rapidly evokes the full stored pattern. Subsequent presentation of overlapping pattern 2 initially evokes a different pattern of activity, but eventually the network settles to the previously stored pattern 1. B: With strong cholinergic modulation, new overlapping patterns can be stored without interference from previous patterns. After learning of pattern 1 , presentation of pattern 2 initially evokes a small portion of pattern 1 , but the suppression of synaptic transmission prevents this from dominating, and the network now stores pattern 2. Subsequent presentation of the degraded version of pattern 2 evokes only pattern 2. recurrent synapses was added to the simulation, accurate completion was performed in a simple recall task (Fig. 5). (N ote that we focus on the completion of spatial patterns of activity, without specific timing requirements.) Additional tests of this model are being performed to further dissect how cellular cholinergic effects shape collective behavior in this region, including $G A B A_{B}$ effects.

\section{Full Network Simulation of Episodic Memory Function}

The models of different hippocampal subregions have been combined in a full network simulation of episodic memory function. $M$ any theories of hippocampal function have tended to describe the function of different subregions separately, but it is important to understand how these regions interact continuously during the sequential encoding and retrieval of individual memories. Recent articles have summarized this network model of
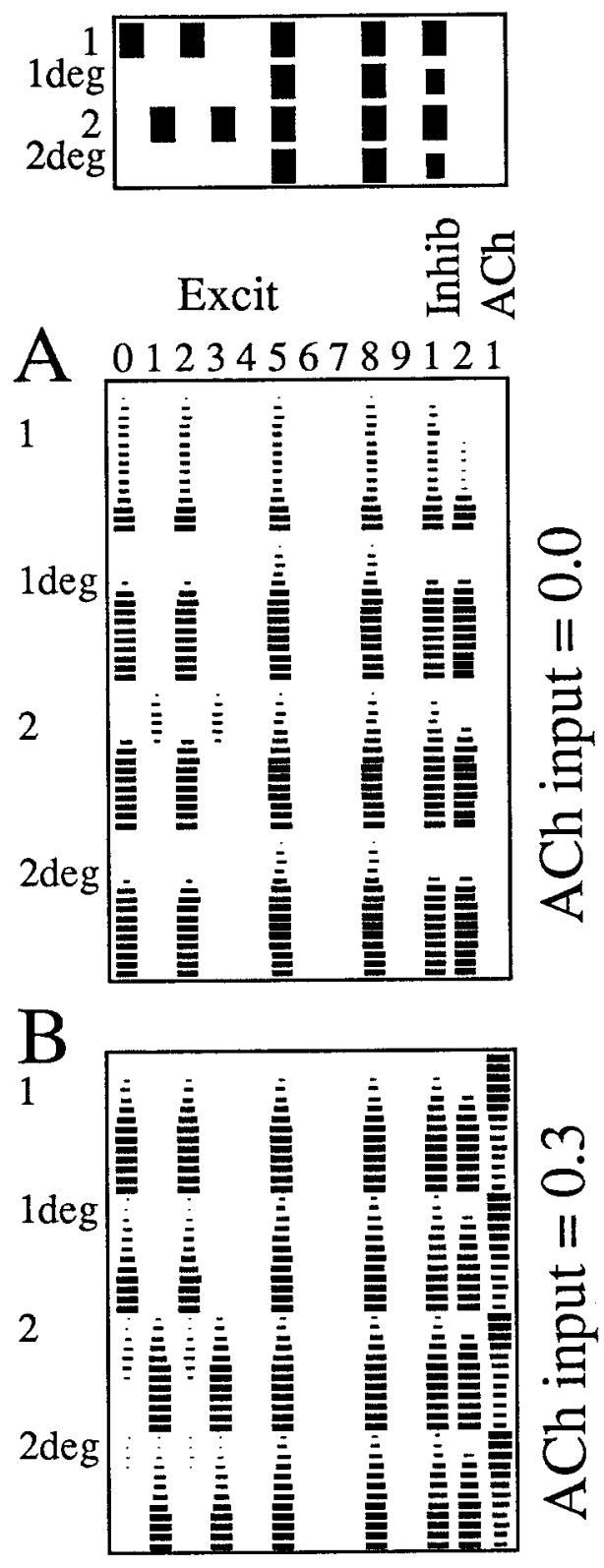
A. Response to complete input pattern
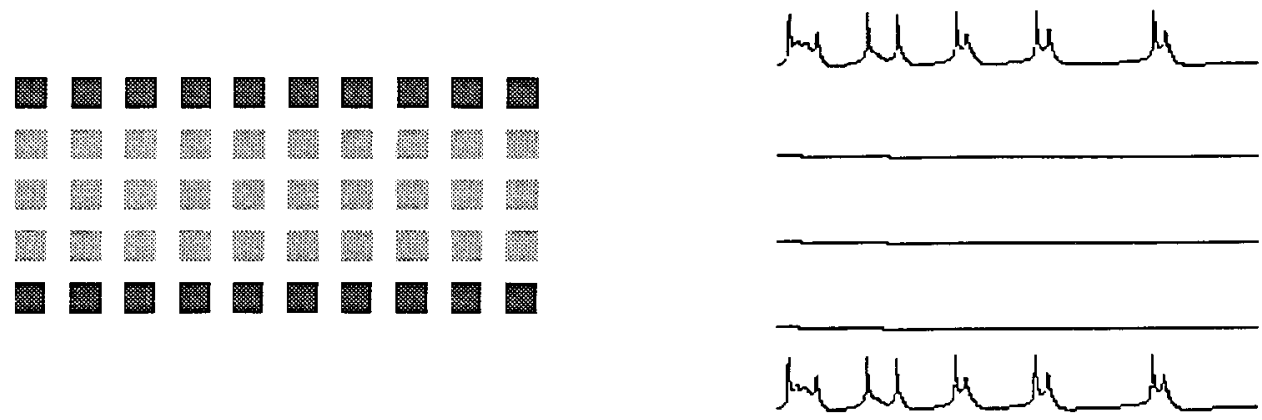

B. Response to degraded input pattern (no learning)
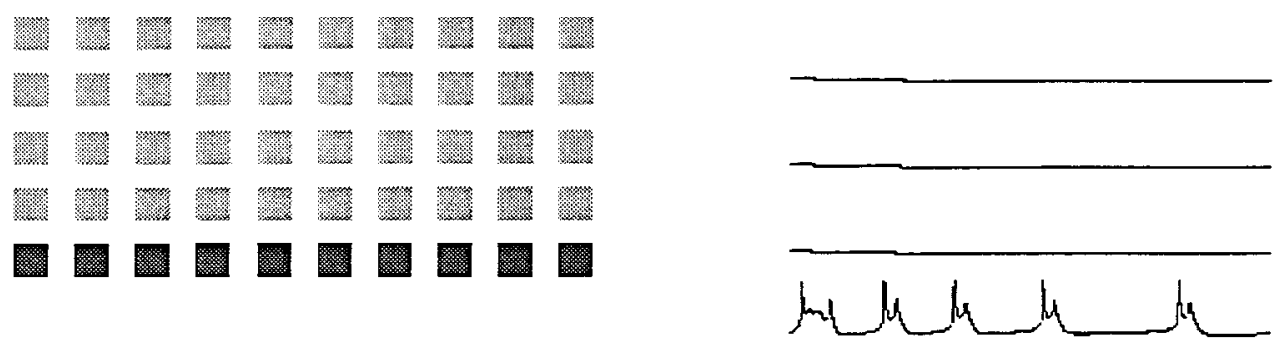

C. Response to degraded input pattern (after learning)

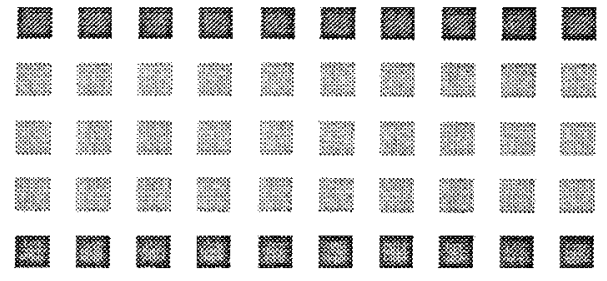

FIGURE 5. Patterns are accurately completed in a biophysical simulation of region CA3. Each square in the left column represents the activity level of a single CA3 pyramidal cell. The gray scale corresponds to membrane potential measured at the soma, with darker values indicating greater depolarization. The right column shows the time series from the first cell in rows 1 through 5 (top to bottom). A: The response of the network to an input pattern during
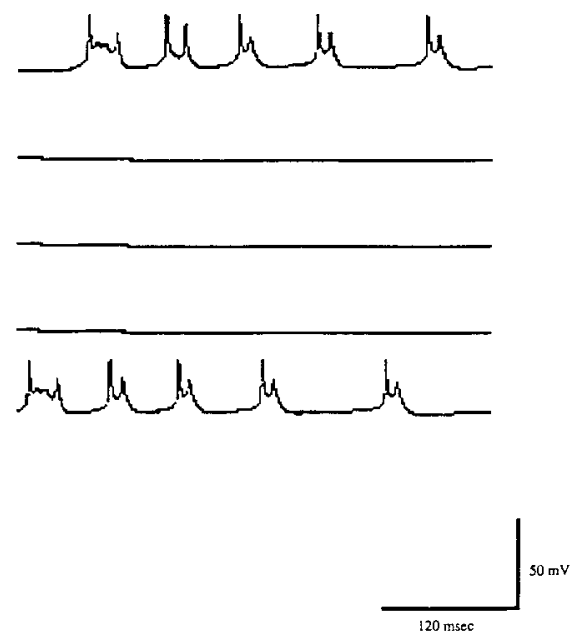

learning. B: The response of the network to a degraded version of the input pattern without learning. C: After learning, the network responds to the degraded pattern with accurate completion of the missing elements of the spatial pattern. Note that we focus on the spatial pattern of activation across a period of time. More detailed dynamic networks will analyze whether the delay in spiking of the cell undergoing completion is a problem for network function. 
episodic memory in the hippocampus ( $\mathrm{H}$ asselmo and Stern, 1996; $\mathrm{H}$ asselmo et al., 1996). An initial focus of this work was to model the effects of scopolamine on encoding of episodic memories in human subjects. This required simulation of the dynamics of both free recall and recognition.

An example of the encoding and free recall of memory patterns in the network is shown in Figure 6. As can be seen in the figure, distributed patterns of activity representing item and context are presented to entorhinal cortex layer II. The item and context portions of these patterns are encoded in the form of a sparse representation in the dentate gyrus. $N$ ote that these are episodic representations specific to a particular input, not the semantic representations which would be repeatedly activated by words in different contexts. The dentate gyrus representations are passed along to region $\mathrm{CA} 3$, where longitudinal association fibers mediate formation of attractors for each item and for context, and form associations between the context and the different items. The attractors formed in region CA3 are then associated with selforganized representations in region $C A 1$, which can activate the full encoded pattern in entorhinal cortex layer IV.

Recently, the model has been used to simulate experimental data on the effects of scopolamine on encoding of word lists by human subjects (G honeim and M ewaldt, 1975; Peterson, 1977). $D$ ifferent networks were trained on lists of 16 words each. Free recall of these words was obtained by repeatedly presenting the network with the experimental context-this resulted in activation of individual attractor states corresponding to individual stored items (words). Recognition of these words was tested by presenting the network with the individual item and evaluating whether the network generated the corresponding experimental context.

Implementing the effects of scopolamine (by blocking acetylcholine effects in the model) showed selectivity similar to that seen in human experiments. The free recall or recognition of previously encoded words was not impaired by scopolamine. The free recall of words encoded under the influence of scopolamine was greatly reduced, but the recognition of these same words was not strongly influenced. Thus, the model was capable of simulating the selective effects of scopolamine on human memory function.

In preliminary work, this network simulation has also been used to replicate the possible dynamics of temporally graded retrograde amnesia (M cClelland et al., 1995). As shown in Figure 7, consolidation mechanisms can be simulated by adding recurrent connections to the neocortical component of the model (entorhinal cortex layer IV) and assuming faster rates of synaptic modification within the hippocampus compared to slow rates of synaptic modification within entorhinal cortex. When the network is initially trained on a set of six memories, new attractor states are formed in the hippocampus but not within entorhinal cortex. Initially, degraded input cues presented to entorhinal cortex layer IV do not evoke the full attractor state. This corresponds to the impairment of recently learned memories after hippocampal lesions. Subsequently, consolidation is simulated by the repetitive reactivation of different attractor states by broadly distributed homogeneous depolarization in region CA3. The repetitive reinstatement of activity patterns in entorhinal cortex layer IV results in the strengthening of internal connections, such that entorhinal cortex is eventually able to respond to degraded cues with the full attractor state. This corresponds to the sparing of more remote episodic memory after hippocampal lesions.

\section{DISCUSSION}

\section{What Do We Know Now That We Did Not Know Before?}

These computational models demonstrate how memory function at a behavioral level could be related to the interaction of populations of neurons within the hippocampal formation. In particular, the model allows us to link the behavioral effects of drugs which block acetylcholine receptors to the blockade of specific cellular effects of acetylcholine, demonstrating how loss of this modulation can impair the encoding of new information in the hippocampus.

\section{What Did the Model Accomplish That Could Not Have Been Accomplished by Simpler Verbal-Qualitative Reasoning?}

Computational modeling is particularly important for understanding the role of diffuse modulatory influences. Acetylcholine causes a number of different physiological effects, suppressing both excitatory and inhibitory synaptic transmission, enhancing synaptic modification, depolarizing both pyramidal cells and inhibitory interneurons, and suppressing the adaptation of pyramidal cells. The decrease in synaptic modification might be understood as a clear decrease in memory encoding rate using simple verbal-qualitative reasoning. H owever, the rate of synaptic modification depends very strongly on the activation dynamics of individual subregions. Understanding the combined influence of a range of different effects which push total activity in different directions requires the use of modeling techniques.

For example, consider the cholinergic suppression of synaptic transmission. This effect initially appears to be paradoxical. W hy would a substance which enhances the encoding of new information strongly suppress excitatory synaptic transmission? When I first discovered the selectivity of cholinergic suppression for intrinsic but not afferent fibers in piriform cortex in 1989, I did not have a clear notion of why this effect would be important. H owever, when placed in the context of the encoding and retrieval dynamics of neural network models of associative memory (Anderson et al., 1977; H opfield, 1982; Amit, 1989), this effect became perfectly clear (see Fig. 2).

\section{How Does This Model Relate to Others in This Issue?}

As mentioned above, the models presented here are closely related to the theories developed initially by $D$ avid $M$ arr (1971) and extended by a number of researchers ( $\mathrm{MCN}$ aughton and M orris, 1987; Levy, 1989; M cN aughton, 1991; Treves and Rolls, 
1992, 1994; O 'Reilly and M cClelland, 1994; Levy et al., 1995; $\mathrm{M} \mathrm{cClelland}$ and Goddard, 1996). However, the use of explicit simulations has allowed more detailed analysis of many issues not directly addressed in previous theoretical articles.

\section{Region CA1 Performs Comparison}

As described above, the model of region $\mathrm{CA} 1$ evaluated the MCNaughton (1991) hypothesis that the Schaffer collaterals mediate heteroassociative memory function, showing that this function is most efficient when cholinergic suppression of synaptic transmission is present at the Schaffer collaterals during encoding (H asselmo and Schnell, 1994). Efficient heteroassociative encoding is necessary if region CA1 is to perform as the locus of a comparison between CA3 output and the afferent input from entorhinal cortex layer III (Levy, 1989; Eichenbaum and Buckingham, 1990; H asselmo and Stern, 1996; H asselmo et al., 1996). In addition, a comparison of recall with afferent input is only useful

$\begin{array}{ll}\text { Input } & \text { Successful } \\ \text { Patterns } & \text { Recall: } \\ \text { List 1 } & \text { List 1 }\end{array}$

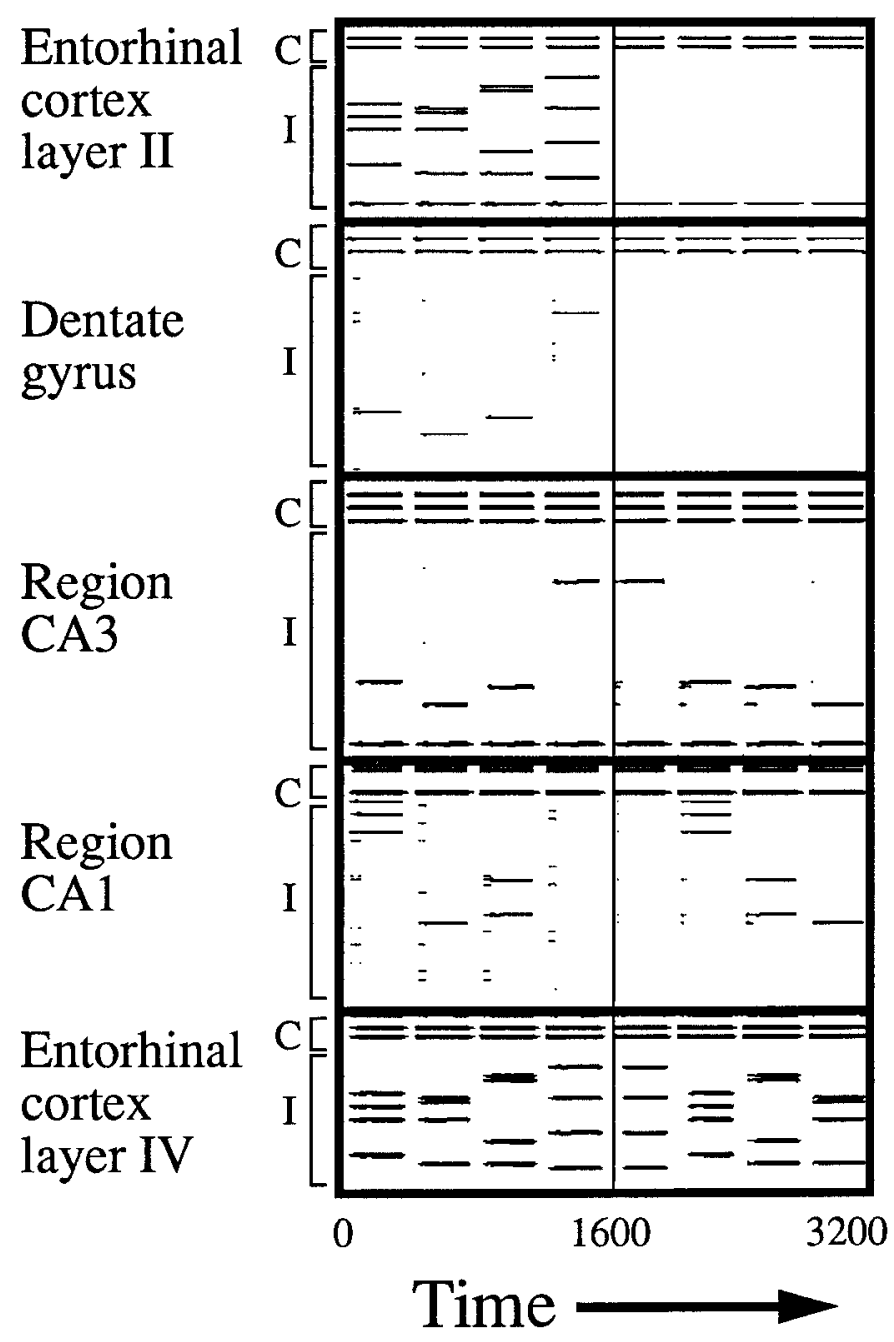

if it can regulate the function of the network. This regulation could be implemented as a change in cholinergic or GABAergic modulation regulated by the medial septum. The hypothesis that the Schaffer collaterals mediate heteroassociative memory function contrasts with the work of Treves and Rolls (1994) which downplays the direct entorhinal cortex input, focusing on selforganization of the Schaffer collaterals under the driving influence of activity in region $\mathrm{CA} 3$.

\section{Region CA3 Associates Context and Item}

Theories of region CA3 as an autoassociative memory (M C$N$ aughton and M orris, 1987) have been extended with analyses of CA3 as an attractor network (Treves and Rolls, 1992, 1994; Bennett et al., 1994; H asselmo et al., 1995). In these models, it is necessary that afferent input should be stronger than recurrent excitation during encoding, allowing clamping of network activity to the input patterns. In contrast, during retrieval the recurrent excitation should dominate over the afferent input. These effects were obtained here by changing the relative strength of recurrent excitation with cholinergic modulation. However, Treves and Rolls (1992) have presented an alternative mechanism for addressing the same functional problem. They propose that the very strong mossy fiber inputs from dentate gyrus granule cells clamp activity in region CA3 during encoding, and that reduction in dentate gyrus activity during retrieval allows recurrent excitation to dominate, with retrieval cues provided by the weaker perforant path input to region CA3 (Treves and Rolls, 1992). It is plausible that both mechanisms contribute to encoding dynamics, since experimental data have shown both the cholinergic suppression of excitatory transmission and the strong influence of individual mossy fiber inputs. O ne difficulty with theTreves and Rolls model

FIGURE 6. Encoding and retrieval of episodic memory patterns in the full network simulation of the hippocampus. The time steps of the simulation are plotted horizontally, while the activities of different neurons in each subregion of the hippocampal simulation are plotted vertically (width of black lines represents activity at each time step). During the first 1,600 time steps, four different input patterns are presented to entorhinal cortex layer II. Each of these input patterns shares a representation of experimental context (active lines on top, marked with " $\mathrm{C}$ ") and have different patterns representing individual memorized items (i.e., words, marked with "I"). The context activity evokes activity at the top of each region. The item activity evokes sparse activity in the remainder of each region. Thus, in the dentate gyrus, a single active neuron constitutes a sparse representation of each item which is passed on to region CA3- where the activity is encoded as an attractor state. Region CA3 attractor states are associated with region CA1 activity, and with the full patterns in entorhinal cortex layer IV. During steps $1,600-3,200$, presentation of the experimental context only (two active lines on top), results in activation of the context representation in dentate gyrus and region CA3. Context activity in region CA3 spreads activity to the item attractors. 0 ne of these attractor states rapidly dominates, spreading activity on to region CA1 and entorhinal cortex layer IV, constituting successful recall of the first memory. Subsequently, adaptation prevents reactivation of the same attractor state in region $\mathrm{CA} 3$, and context can sequentially evoke the other stored memories. Note that retrieval does not necessarily take place in the same order as encoding. 


\section{Learning Recall Consolidation Recall}

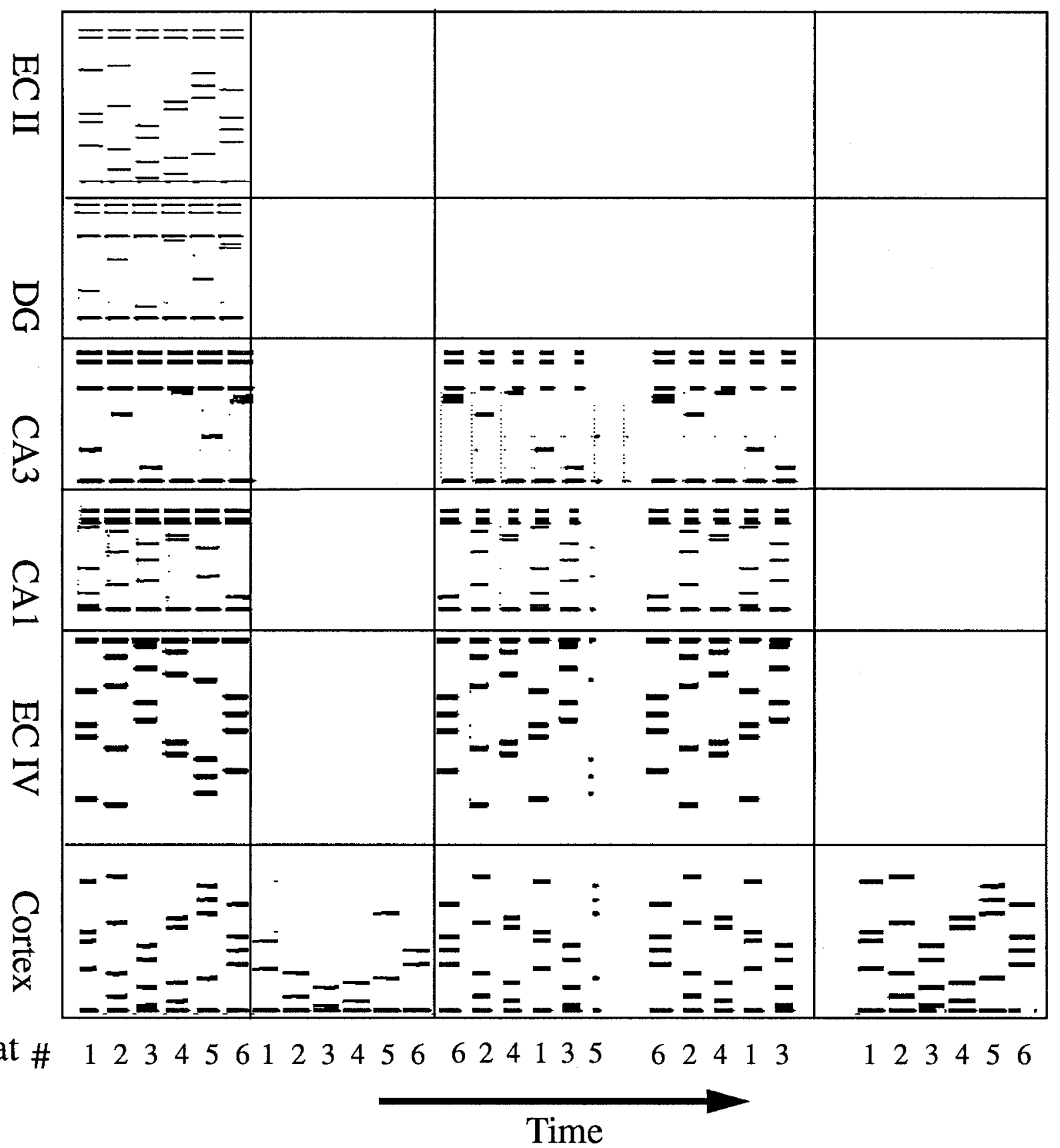

FIGURE 7. Simulation of consolidation in the network simulation of hippocampal episodic memory function. This simulation has the additional feature that slowly modifiable recurrent connections are added to entorhinal cortex layer IV to mediate slower formation of attractor states in that network. Different time steps of the simulation are plotted horizontally, while the activities of different neurons in each subregion of the hippocampus are plotted vertically (vertical width of black lines represents activity of individual neurons on each time step). $0 \mathrm{n}$ the left, six different episodes are presented sequentially to entorhinal cortex layers II and III. Each episode shares a context on the top of each region and has different item elements on the bottom. During learning, sparsely distributed representations of these different episodes are rapidly formed in the dentate gyrus and passed on to region CA3 to be rapidly encoded as attractor states. During a subsequent phase in the model, the response of entorhinal cortex layer IV to degraded input patterns is tested. Each degraded pattern contains two active elements, and the full item attractors are not activated. D uring a long consolidation phase, homogeneous depolarization of region CA3 results in the sequential free recall of different attractors in region CA3 which evoke the corresponding full patterns in entorhinal cortex layer IV. Gradually, the strengthening of recurrent connections in entorhinal cortex layer IV results in the formation of attractor states. Subsequently, when the network is tested with input to entorhinal cortex layer IV alone, the degraded patterns evoke full attractor states for all six of the stored memories. The difference in retrieval characteristics in entorhinal cortex layer IV could correspond to the different stages of temporally graded retrograde amnesia, as discussed in previous modeling work (M cC lelland et al., 1995). 
is the necessity of weakening or removing the mossy fiber input during retrieval. H owever, cholinergic modulation does increase the responsiveness of dentate gyrus granule cells (Bilkey and Goddard, 1985) and could thus regulate the level of dentate gyrus activity during encoding.

\section{Dentate Gyrus Forms Sparse Representations}

The representation of the dentate gyrus utilized here draws on previous theories that the dentate gyrus sets up sparse representations with less overlap than the entorhinal cortex input ( $\mathrm{M}$ CN aughton and Morris, 1987; M CN aughton, 1991; Treves and Rolls, 1994; O'Reilly and McClelland, 1994). However, the actual implementation of this phenomenon differs considerably. Some of these earlier theories do not emphasize synaptic modification at the perforant path input to the dentate gyrus- focusing on the divergent nature of the connections from entorhinal cortex as the basis for forming sparser representations. Other studies have described how synaptic modification can help to make representations overlap even less (Treves and Rolls, 1994; O 'Reilly and M cClelland, 1994). However, self-organization more effectively decreases the overlap between different patterns during interleaved presentation of individual patterns than when the self-organization must occur in response to single, sequential presentations of input patterns. We found it useful to add modification of inhibition within the dentate gyrus to prevent new patterns from reactivating previously stored representations within the dentate gyrus.

\section{Medial Septum Sets Learning Dynamics}

The model presented here uses feedback regulation of modulatory input from the medial septum to set different dynamical states for encoding and retrieval in the network. 0 ther models in this issue do not focus explicitly on modulatory effects at the cellular level. However, the shift between different processing modes appears to be an essential feature of many more abstract models of hippocampal function. For example, in the work of M urre (M urre et al., 1992; M urre, this issue) an "arousal" node responds to activity of other nodes by turning on learning and injecting noise. In the work of Recce and Harris (1996), the network initially evaluates the hippocampal recall in an orientation mode- if no hippocampal map is recalled, the network enters an "exploration" mode during which new learning takes place; if a hippocampal map is recalled, the network enters a "recall" mode. These different modes of function correspond to differences in animal behavior over longer time periods. It is very possible that the hippocampus undergoes both rapid changes between encoding and retrieval on the time scale of theta cycles and slower changes corresponding to longer-term behavioral state changes. In fact, the physiological data support such a change in state between stages of encoding during theta activity and consolidation mediated by sharp wave activity (Buzsaki, 1989). The changes in dynamics mediated by cholinergic modulation are perfectly consistent with that previous theory. In models which use an explicit computation of error, the medial septum plays an important role in setting the level of learning. For example, in the model of Buhusi and Schmajuk, (1996), the mismatch between actual and predicted US values sets the level of medial septal activity, which provides part of the error signal for modification of connections with the "hidden units" corresponding to the hippocampus. In the model of Gluck and Myers, it has been shown that the effect of acetylcholine blockade on acquisition of eyeblink conditioning can be effectively modeled with a decrease in overall learning rate within the hippocampus (M yers et al., 1996; Gluck and M yers, 1996).

\section{Function of the Full Hippocampal Network}

The modeling research presented here has focused on episodic memory function. However, the model can also be used to simulate experimental data on animal learning of negative patterning (Rudy and Sutherland, 1989). Modeling shows that associative networks in neocortical structures could underlie learning of simple associations, but the self-organization of new, episodic representations such as those formed in this hippocampal model are necessary for learning high-order configurations such as those in negative patterning ( $\mathrm{H}$ asselmo and Cekic, 1996; $\mathrm{H}$ asselmo et al., 1996). The issue of relational learning is more complex (Eichenbaum and Buckingham, 1990; Eichenbaum et al., 1991), because it requires the flexible use of a range of different episodic representations for solving particular problems. To address relational learning, this model needs to be expanded to include multiple interitem associations and the ability to evaluate relational hypotheses on the basis of output. The comparison function of region CA1 in this network model could be very important to relational learning, since it provides a structure in which the output of relational hypotheses generated through chains of associations in region CA3 could be evaluated with regard to information about the current environment arriving directly from the entorhinal cortex.

In this framework, when an animal encounters a new situation in which retrieval of previously learned strategies produces an output which does not match reward contingencies of the environment, then the levels of cholinergic modulation would be increased within the network. This would terminate the previous strong previous attractor, and allow multiple other competing hypotheses to be activated via associative connections in region CA3. Competition between these hypotheses would take place in a manner similar to that which resulted in retrieval of just one out of multiple competing items in free recall. (The previously generated attractor would be at a disadvantage due to adaptation.) Eventually, feedback regulation of cholinergic modulation on the basis of matching in region $C A 1$, or a forced change in modulatory dynamics across different phases of a theta cycle, could allow a single alternative hypothesis to dominate. Learning of this new hypothesis as the correct output would depend upon the level of match with the current environmental conditions arriving from entorhinal cortex. This use of the comparison function to regulate encoding could be the basis for linking cellular level processes to the error-based learning rules used in higher-level models of the role of the hippocampus in conditioning (Gluck and M yers, 1993; Schmajuk and DiC arlo, 1992). The 
formation of sparse representations of episodic information within the hippocampal model may correspond to the formation of place cell responses in the rat hippocampus during exploration of the environment (M uller et al., 1987; M uller and Kubie, 1989; Wilson and MCNaughton, 1993). Thus, this computational model could also be used to address issues of how these representations are formed and altered with regard to environmental cues. The model has recently been modified to include temporal interactions between different patterns of activity in order to address issues such as the relationship of place cell responses to phases of the theta rhythm ( $O$ 'K eefe and Recce, 1993). This recent work resembles the work on encoding and retrieval of temporal sequences of patterns in computational models of region CA3 (M inai and Levy, 1994; Levy et al., 1995).

\section{What New Experimental Directions Are Suggested by This Modeling?}

The modeling presented here provides specific predictions and suggests areas where additional data must be gathered.

\section{Human memory predictions}

Scopolamine should enhance the list strength effect. In the model, the recurrent connections for context become stronger than the recurrent connections for items. This asymmetry in the strength of recurrent connections underlies the greater effect of scopolamine on free recall than on recognition ( $\mathrm{H}$ asselmo and Wyble, 1996). This al so results in a list strength effect in free recall but not recognition (R atcliffe et al., 1990). If an individual item is presented multiple times, it strengthens the recurrent connections for that item and increases the likelihood that these strong items will be retrieved relative to the likelihood of weak items being retrieved. Repeated presentation of some items does not alter the strength of recurrent connections for the context units, and the list strength effect does not appear for recognition. The model predicts that the presence of scopolamine during encoding should enhance the list strength effect for free recall. Items which were presented multiple times will be much more likely to persist during free recall. The proportion of these items recalled will be much higher because of the great decrease in retrieval of items presented only once in the presence of scopolamine.

Scopolamine should enhance proactive interference. Modeling also predicts that blockade of the cholinergic suppression of synaptic transmission should allow retrieval of previously stored associations to interfere with new associations, causing an increase in proactive interference. Scopolamine injected before learning of both $A-B$ associations and $A-C$ associations should cause greater retrieval of $B$ items relative to $C$ items when subjects are presented with the $A$ items and asked to generate both associated items. In addition, scopolamine injected after encoding of A-B associations should cause much greater impairments in the subsequent encoding of A-C associations than in the subsequent encoding of unrelated associations (D -E). Surprisingly few studies of human subjects have addressed effects of scopolamine on cued recall paradigms- possibly due to a weaker effect compared to that on free recall. H owever, lesions which damage cholinergic innervation of the hippocampus appear to cause increases in proactive interference (Van der Linden et al., 1993). Scopolamine should also enhance proactive interference between related trigrams in the Brown-Peterson task (C ermak and Butters, 1972).

Scopolamine should enhance retrieval of previously stored items. Because the retrieval of stored attractor states requires strong recurrent excitation and strong adaptation (to prevent previous attractors from being activated), simulation of the effects of scopolamine enhances the retrieval of patterns (words) stored before the onset of scopolamine effects. Several studies show a small increase in retrieval of words learned before scopolamine injections (Petersen, 1977; Ghoneim and Mewaldt, 1977; Mewaldt and Ghoneim, 1979), supporting the notion that acetylcholine blockade puts the network into a retrieval state. As noted above, the response of the network to familiar items should actually be enhanced at the same time as the response to novel items is greatly decreased. This prediction could be tested with functional magnetic resonance imaging. It has been shown in normal subjects that novel stimuli cause greater activation of the hippocampal formation than familiar stimuli (Stern et al., 1996). Injections of scopolamine should reduce this activation in responseto novel stimuli and may result in greater relative activation in response to familiar patterns.

\section{Animal learning predictions}

This work does not make a strong distinction between the type of representations formed during human episodic memory function and those utilized by animals in performing particular tasks. Thus, predictions of this work are also being tested in animal learning experiments being performed in this laboratory. In particular, the model presented above suggests that injections of scopolamine should cause more difficulty in the encoding of overlapping than the encoding of nonoverlapping sensory stimuli. This prediction is being tested in a rat olfactory associative memory task. In this task, the rats must associate particular pairs of odors with particular responses. The model predicts that scopolamine should cause much greater impairments of the encoding of overlapping odor pairs ( $A-B$ vs. $A-C)$ than the encoding of nonoverlapping odor pairs ( $A-B$ vs. $C-D$ ).

\section{Required data on feedback regulation of cholinergic modulation}

The model presented here makes extensive assumptions about how hippocampal activity influences modulatory input from the medial septum. There are some data suggesting that stimulation of hippocampal output decreases medial septum unit activity (M cLennan and M iller, 1974) and that medial septal activity decreases as stimuli are learned (Berger and Thompson, 1982). H owever, there is remarkably little information about how activity in the hippocampus influences modulation from the medial septum. $\mathrm{N}$ ew experiments in this laboratory will focus on how stimulation of cortical structures will influence activity within basal forebrain nuclei. 
The models presented here also make assumptions about changes in levels of synaptic transmission during different periods of a behavioral task and during different phases of the theta rhythm. These assumptions can be tested experimentally by directly observing how evoked field potentials within the hippocampus change dependent upon behavioral contingencies. Thus, new experiments in this laboratory will test whether field potentials evoked by stimulation of the Schaffer collaterals will change in size during encoding of new information versus retrieval of previously stored information. Changes in excitability of hippocampal pyramidal cells have been shown in different phases of the theta rhythm (Rudell et al., 1980), but that previous work focused on changes of population spikes rather than population excitatory postsynaptic potentials. Experiments in this laboratory will also explore whether synaptic potentials elicited at different phases of the theta rhythm demonstrate changes in modulation of transmission.

\section{REFERENCES}

Aigner T G, Walker DL, M ishkin M (1991) Comparison of the effects of scopolamine administered before and after acquisition in a test of visual recognition memory in monkeys. Behav N eural Biol 55:61-67.

Alvarez P, Zola-M organ S, Squire LR (1994) The animal model of human amnesia-long-term memory impaired and short-term memory intact. Proc N atl Acad Sci U SA 91:5637-5641.

Alvarez P, Zola-M organ S, Squire LR (1995) Damage limited to the hippocampal region produces long-lasting memory impairment in monkeys. J Neurosci 15:3796-3807.

Amaral DG, Witter M P (1989) The 3-dimensional organization of the hippocampal formation $-\mathrm{A}$ review of anatomical data. N euroscience 31:571-591.

Amit D (1989) M odelling brain function. Cambridge University Press: Cambridge, UK.

Anderson JA, Silverstein JW, Ritz SA, Jones RS (1977) Distinctive features, categorical perception, and probability learning: some applications of a neural model. Psychol Rev 84:413-451.

Ault B, N adler JV (1982) Baclofen selectively inhibits transmission at synapses made by axons of CA3 pyramidal cells in the hippocampal slice. J Pharmacol Exp Ther 223:291-297.

Baddeley AD, Warrington EK (1970) Amnesia and the distinction between long- and short-term memory. J Verb Learning Verb Behav 9:176-189.

Barkai E, H asselmo M E (1994) M odulation of theinput/output function of rat piriform cortex pyramidal cells. J N europhysiol 72:644-658.

Beatty W W, Butters N , Janowsky D S (1986) Patterns of memory failure after scopolamine treatment: implications for cholinergic hypotheses of dementia. Behav N eural Biol 45:196-211.

Benardo LS, Prince DA (1982) Ionic mechanisms of cholinergic excitation in mammalian hippocampal pyramidal cells. Brain Res 249:333-344.

Bennett M R, Gibson W G, Robinson J (1994) Dynamics of the CA3 pyramidal neuron autoassociative memory network in the hippocampus. Philos Trans R Soc Lond [Biol] 343:167-187.

Berger TW, Thompson RF (1982) H ippocampal cellular plasticity during extinction of classically-conditioned nictitating membrane behavior. Behav Brain Res 4:63-76.

Bilkey D K, Goddard GV (1985) M edial septal facilitation of hippocam- pal granule cell activity is mediated by inhibition of inhibitory interneurons. Brain Res 361:99-106.

Bland BH , Colom LV (1993) Extrinsic and intrinsic properties underlying oscillation and synchrony in limbic cortex. Prog Neurobiol 41:157-208.

Blizter RD , Gil O, Landau EM (1990) Cholinergic stimulation enhances long-term potentiation in the $\mathrm{CA} 1$ region of rat hippocampus. N eurosci Lett 119:207-210.

Buhusi CV, Schmajuk N A (1996) Attention, configuration and hippocampal function. Hippocampus 6:621-642.

Burgard EC, Sarvey JM (1990) M uscarinic receptor activation facilitates the induction of long-term potentiation (LTP) in the rat dentate gyrus. Neurosci Lett 116:34- 39.

Burgess N, Recce M, O 'Keefe J (1994) A model of hippocampal function. N eural N etworks 7:1065-1081.

Buzsaki G (1989) Two-stage model of memory trace formation: a role for 'noisy' brain states. N euroscience 31:551-570.

Buzsaki G, Leung LWS, Vanderwolf CH (1984) Cellular bases of hippocampal EEG in the behaving rat. Brain Res Rev 6:139-171.

Carpenter GA, Grossberg S (1993) Normal and amnesic learning, recognition and memory by a neural model of cortico-hippocampal interactions. Trends N eurosci 16:131-137.

Cermak LS, Butters N (1972) The role of interference and encoding in the short-term memory deficits of Korsak off patients. N europsychologia 10:89-95.

Chappell M , H umphreys M S (1994) An auto-associative neural network for sparse representations: Analysis and application to models of recognition and cued recall. Psychol Rev 101:103-128.

Colbert CM , Levy W B (1992) Electrophysiological and pharmacological characterization of perforant path synapses in CA1: mediation by glutamate receptors. J Neurophysiol 68:1-7.

Cole AE, Nicoll RA (1984) Characterization of a slow cholinergic postsynaptic potential recorded in vitro from rat hippocampal pyramidal cells. J Physiol (Lond) 352:173-188.

Corkin S (1984) Lasting consequences of bilateral medial temporal lobectomy: clinical course and experimental findings in H .M. Semin N eurol 4:249-259.

Crow TJ, Grove-W hite IG (1973) An analysis of the learning deficit following hyoscine administration to man. Br J Pharmacol 49:322327.

Drachman DA (1978) Central cholinergic system and memory. In: Psychopharmacology: a generation of progress (Lipton M A, D iM ascio A, Killam KF, eds), pp. 651-662. N ew York: Raven Press.

Eichenbaum H, Buckingham J (1990) Studies on hippocampal processing: experiment, theory and model. In: Learning and computational neuroscience: foundations of adaptive networks ( $G$ abriel $M, M$ oore), eds), pp 171-231. Cambridge, M A: M IT Press.

Eichenbaum H, Mathews OP, Cohen N (1989) Further studies of hippocampal representation during odor discrimination learning. Behav N eurosci 103:1207-1216.

Eichenbaum H, O tto TA, W ible CG, Piper JM (1991) Building a model of the hippocampus in olfaction and memory. In: O Ifaction: a model system for computational neuroscience (Davis JL, Eichenbaum $H$, ed), pp 167-210. Cambridge, M A: M IT Press.

Eichenbaum H, Otto T, Cohen NJ (1992) The hippocampus- what does it do? Behav N eural Biol 57:2-36.

Eichenbaum H, Otto T, Cohen NJ (1994) Two functional components of the hippocampal memory system. Behav Brain Sci 17:449-518.

Frith CD, Richardson JTE, Samuel M, Crow TJ, M CKenna PJ (1984) The effects of intravenous diazepam and hyoscine upon human memory. Q J Exp Psychol 36A:133-144.

G affan D , H arrison S (1989) Place memory and scene memory: effects of fornix transection in the monkey. Exp Brain Res 74:202-212.

Ghoneim M M , M ewaldt SP (1975) Effects of diazepam and scopolamine on storage, retrieval and organization processes in memory. Psychopharmacologia 44:257-262.

Ghoneim M M, M ewaldt SP (1977) Studies on human memory: the 
interactions of diazepam, scopolamine and physostigmine. Psychopharmacology 52:1-6.

Gillund G, Shiffrin RM (1984) A retrieval model of both recognition and recall. Psychol Rev 91:1-67.

Gluck MA, Myers CE (1993) Hippocampal mediation of stimulus representation: a computational theory. $\mathrm{H}$ ippocampus 3:491-516.

Gluck M A, M yers CE (1996) Integrating behavioral and physiological models of hippocampal function. $\mathrm{H}$ ippocampus 6:643-653.

Granger R, Wiebe SP, Taketani M, Lynch G (1996) Distinct memory circuits comprising the hippocampal region. H ippocampus 6:567578.

H agan JJ, Salamone JD, Simpson J, Iversen SD, M orris RGM (1988) Place navigation in rats is impaired by lesions of medial septum and diagonal band but no nucleus basalis magnocellularis. Behav Brain Res 27:9-20.

$H$ asselmo ME (1995) N euromodulation and cortical function: modeling the physiological basis of behavior. Behav Brain Res 65:1-27.

$\mathrm{H}$ asselmo ME, Barkai E (1995) Cholinergic modulation of activitydependent synaptic plasticity in rat piriform cortex. J Neurosci 15:6592-6604

H asselmo M E, Bower JM (1992) Cholinergic suppression specific to intrinsic not afferent fiber synapses in rat piriform (olfactory) cortex. J Neurophysiol 67:1222-1229.

H asselmo M E, Cekic M (1996) Suppression of synaptic transmission may allow combination of associative feedback and self-organizing feedforward connections in the neocortex. Behav Brain Res 79:153161.

$H$ asselmo ME, Schnell E (1994) Laminar selectivity of the cholinergic suppression of synaptic transmission in rat hippocampal region CA1: computational modeling and brain slice physiology. J Neurosci 14:3898-3914.

$H$ asselmo ME, Schnell E, Barkai E (1995) Learning and recall at excitatory recurrent synapses and cholinergic modulation in hippocampal region CA3. J N eurosci 15:5249-5262.

$\mathrm{H}$ asselmo ME, Stern CE (1996) Linking LTP to network function: a simulation of episodic memory in the hippocampal formation. In: Long-term potentiation, vol. 3 (Baudry M , D avis], eds), Cambridge, M A: MIT Press.

$H$ asselmo M E, Wyble B, Stern CE (1996) A model of human memory function based on the cellular physiology of the hippocampal formation. In: Neural networks for neuropsychologists (Parks R, Levine D, eds), M IT Press: C ambridge, M A.

$H$ intzman DL (1988) Judgments of frequency and recognition memory in a multipletrace memory model. Psychol Rev 95:528-551.

H opfield J] (1982) N eural networks and physical systems with emergent collective computational abilities. Proc N atl Acad Sci USA 79:25542558.

H ounsgaard J (1978) Presynaptic inhibitory action of acetylcholine in area CA1 of the hippocampus. Exp N eurol 62:787-797.

Kesner RP, N ovak JM (1982) Serial position curve in rats: role of the dorsal hippocampus. Science 218:173-174.

Levy W B (1989) A computational approach to hippocampal function. In: Computational models of learning in simple neural systems (H awkins R D, Bower G H , ed), pp 243-305. O rlando, FL: Academic Press.

Levy WB, Colbert CM, Desmond NL (1990) Elemental adaptive processes of neurons and synapses: a statistical/computational perspective. In: N euroscience and connectionist theory (Gluck M A, Rumelhart DE, ed), pp 187-236. Hillsdale, N J: Lawrence Erblaum Assoc.

Levy W B, Wu X, Baxter RA (1995) Unification of hippocampal function via computational/encoding considerations. Int J Neural Syst 6:7180.

Liljenstrom H, H asselmo M E (1995) C holinergic modulation of cortical oscillatory dynamics. J N europhysiol 74:288-297.

M adison DV, N icoll RA (1984) C ontrol of the repetitive discharge of rat CA1 pyramidal neurones in vitro. J Physiol (Lond) 354:319-331.
M adison DV, Lancaster B, Nicoll RA (1987) Voltage clamp analysis of cholinergic action in the hippocampus. J N eurosci 7:733-741.

$M$ arr D (1971) Simple memory: a theory for archicortex. Philos Trans R Soc [Biol] 262:23-81.

McClelland JL, M cNaughton BL, O Reilly R (1995) Why are there complementary learning systems in the hippocampus and neocortex: insights from the successes and failures of connectionist models of learning and memory. Psychol Rev 102:419-457.

M CClelland JL, Goddard NH (1996) Considerations arising from a complementary learning systems perspective on hippocampus and neocortex. Hippocampus 6:654-665.

McLennan H, M iller JJ (1974) The hippocampal control of neuronal discharges in the septum of the rat. J Physiol (Lond) 237:607-624.

M cN aughton BL (1991) Associative pattern completion in hippocampal circuits: N ew evidence and new questions. Brain Res Rev 16:193220.

M cN aughton BL, Barnes CA (1990) From cooperative synaptic enhancement to associative memory: bridging the abyss. Semin N eurosci 2:403-416.

M cN aughton BL, M orris RGM (1987) H ippocampal synaptic enhance ment and information storage within a distributed memory system. Trends N eurosci 10:408-415.

Metcalfe J, M urdock BB (1981) An encoding and retrieval model of single-trial free recall. J Verb Lrn Verb Behav 20:161-189.

Mewaldt SP, Ghoneim MM (1979) The effect and interactions of scopolamine, physostigmine and methamphetamine on human memory. Pharmacol Biochem Behav 10:1205-1210.

$M$ inai AA, Levy W B (1994) Setting the activity level in sparse random networks. N eural Comp 6:83-97.

M izumori SJY, M CN aughton BL, Barnes CA, Fox KB (1989) Preserved spatial coding in hippocampal CA1 pyramidal cells during reversible suppression of CA3C output: evidence for pattern completion in hippocampus. J N eurosci 9:3915-3928.

M izumori SJY, Perez GM , Alvarado M C, Barnes CA, M CN aughton BL (1990) Reversible inactivation of the medial septum differentially affects two forms of learning in rats. Brain Res 528:12-20.

Muller RU, Kubie JL (1989) The firing of hippocampal place cells predicts the future position of freely moving rats. J Neurosci 9:4101-4110.

Muller RU, Kubie JL, Ranck JB (1987) Spatial firing patterns of hippocampal complex-spike cells in a fixed environment. J N eurosci 7:1935-1950.

Murre JM J, Phaf RH, Wolters G (1992) CALM : categorizing and learning module. N eural N etworks 5:55-82.

$M$ yers $C E$, Ermita $B R, H$ arris $K, H$ asselmo $M E$, Solomon $P$, G luck $M A$ (1996) A computational model of cholinergic distruption of septohippocampal activity in classical eyeblink conditioning. Neurobiol Learning M emory 66:51-66.

0 'Keefe J, Recce M (1993) Phase relationship between hippocampal place units and the EEG theta rhythm. H ippocampus 3:317-330.

0 'Reilly RC, M cClelland JL (1994) H ippocampal conjunctive encoding, storage and recall: avoiding a trade-off. H ippocampus 4:661-682.

Peterson RC (1977) Scopolamine induced learning failures in man. Psychopharmacology 52:283-289.

Q uirk GJ, M uller RU, Kubie JL, Ranck JB (1992) The positional firing properties of medial entorhinal neurons: description and comparison with hippocampal place cells. J N eurosci 12:1945-1963.

Ratcliff R, Clark SE, Shiffrin RM (1990) List-strength effect: I. D ata and discussion. J Exp Psychol Learn M em Cogn 16:163-178.

Recce M , H arris KD (1996) M emory for places: A navigational model in support of $M$ arr's theory of hippocampal function. Hippocampus 6:735- 748.

Richardson JTE, Frith CD, Scott E, Crow TJ, Cunningham-O wens D (1984) The effects of intravenous diazepam and hyoscine upon recognition memory. Behav Brain Res 14:193-199.

Rudell AP, Fox SE, Ranck JB (1980) H ippocampal excitability phaselocked to the theta rhythm in walking rats. Exp N eurol 68:87-96. 
Rudy JW, Sutherland RJ (1989) The hippocampal formation is necessary for rats to learn and remember configural discriminations. Behav Brain Res 34:97-109.

Ruppin E, Yeshurun $Y$ (1991) Recall and recognition in an attractor neural network model of memory retrieval. Connection Sci 3:381399.

Schmajuk NA, DiCarlo JJ (1992) Stimulus configuration, classical conditioning, and hippocampal function. Psychol Rev 99:268-305.

Schwindt PC, Spain WJ, Foehring RC, Stafstrom CE, C hubb M C, C rill WE (1988) Slow conductances in neurons from cat sensorimotor cortex and their role in slow excitability changes. J Neurophysiol 59:450-467.

Scoville W B, M ilner B (1957) Loss of recent memory after bilateral hippocampal lesions. J N eurol N eurosurg Psychiatry 20:11-21.

Stern CE, Corkin S, G onzalez RG , G uimaraes AR, Baker JB, Jennings PJ, Carr CA, Sugiura RM, Vedantham V, Rosen BR (1996) The hippocampal formation participates in novel picture encoding: evidence from functional magnetic resonance imaging. Proc $\mathrm{N}$ atl Acad Sci USA 93:8660-8665.

Stewart M, Fox SE (1989) 2 populations of rhythmically bursting neurons in rat medial septum are revealed by atropine. J N europhysiol 61:982-993.

Stewart M , Fox SE (1990) D o septal neurons pace the hippocampal theta rhythm? Trends N eurosci 13:163-168.

Sutherland RJ, Wishaw IQ, Regehr JC (1982) Cholinergic receptor blockade impairs spatial localization by use of distal cues in the rat. J Comp Physiol Psychol 96:563-573.

Swartzwelder HS, Lewis DV, Anderson WW, Wilson WA (1987) Seizure-like events in brain slices: suppression by interictal activity. Brain Res 410:362-366.

Tang AC, H asselmo M E (1994) Selective suppression of intrinsic but not afferent fiber synaptic transmission by baclofen in the piriform (olfactory) cortex. Brain Res 659:75-81.

Traub RD, Wong RKS, M iles R, M ichelson H (1991) A model of a CA3 hippocampal pyramidal neuron incorporating voltage-clamp data on intrinsic conductances. J Neurophysiol 66:635-650.

Treves A (1995) Q uantitative estimate of the information relayed by the Schaffer collaterals. J Comput N eurosci 2:259-272.

Treves A, Rolls ET (1992) Computational constraints suggest the need for two distinct input systems to the hippocampal CA3 network. H ippocampus 2:189-200.

Treves A, Rolls ET (1994) Computational analysis of the role of the hippocampus in memory. H ippocampus 4:374-391.

Troyer TW (1996) Feeforward H ebbian learning with nonlinear output units- a Lyapunov approach. N eural N etworks 9:321-328.

Valentino RJ, Dingledine R (1981) Presynaptic inhibitory effect of acetylcholine in the hippocampus. J N eurosci 1:784- 792.

Van der Linden M, Bruyer R, Roland J, Schils JP (1993) Proactive interference in patients with amnesia resulting from anterior communicating artery aneurysm. J C lin Exp N europsychol 15:525-536.

Whishaw IQ (1989) Dissociating performance and learning deficits on spatial navigation tasks in rats subjected to cholinergic muscarinic blockade. Brain Res Bull 23:347-358.

W igstrom H , Gustafsson B, H uang Y-Y, Abraham W C (1986) H ippocampal long-term potentiation is induced by pairing single afferent volleys with intracellularly injected depolarizing current pulses. Acta Physiol Scand 126:317-319.

Wilson M A, M cNaughton BL (1993) Dynamics of the hippocampal ensemble code for space. Science 261:1055-1058.

Yamamoto C, Kawai N (1967) Presynaptic action of acetylcholine in thin sections from the guinea-pig dentate gyrus in vitro. Exp $\mathrm{Neurol}$ 19:176-187. 